\title{
Smart Service Lifecycle Management: A Framework and Use Case
}

\author{
Mike Freitag $^{1}$ and Stefan Wiesner ${ }^{2}$ \\ ${ }^{1}$ Fraunhofer IAO, \\ Nobelstraße 12, 70569 Stuttgart, Germany \\ ${ }^{2}$ BIBA - Bremer Institut für Produktion und Logistik GmbH at the University of Bremen, \\ Hochschulring 20, 28359 Bremen, Germany
}

\begin{abstract}
This paper focuses on the growing importance of offering Smart Services by manufacturing companies, which are enabled through the increasing amount of data available following Industry 4.0 implementation. Gradually, product-oriented industries are turning into service-oriented industries, where customers are much more involved in developing and delivering services than in developing and delivering products. The ability to offer Smart Services creates a competitive advantage for a company, as it can provide individually configured value-added services to the customer. However, expert interviews and work with industrial use cases show that the knowledge how to realize such Smart Services is still rudimental, in spite of high expectations. Therefore, a Smart Service Lifecycle Management is introduced, formalizing the support needs of the industry and the phases of the lifecycle in a framework, covering business, service and network elements. Parts of this framework has been successfully applied to develop a Monitoring Service for an industrial use case in video surveillance.
\end{abstract}

Keywords: Smart Service, Industry 4.0, Service Lifecycle, Service Engineering, Product-Service System

\section{Introduction}

For manufacturing companies it is becoming increasingly important to offer services in addition to their products. Thereby, it is possible to focus on new target groups through innovative business models [1,2]. Gradually product-oriented industries are turning into service-oriented industries where customers are much more involved in developing and delivering services than in developing and delivering products $[3,4,5]$.

The implementation of Industry 4.0 is a catalyst and accelerator of change. For these reasons, integrated development of products and services is becoming increasingly important $[6,7]$. On this way the dependencies and interactions between the product and the service along their lifecycles are getting relevant for companies when they want to servitize their business [6,7]. An example of such an integrated approach are Smart Services. For example they can help gather and evaluate information and data, simplify machine maintenance processes or optimize industrial value chains. This causes profound changes for manufacturing companies in the medium and long term. 
By offering an attractive bundle of smart products and smart services the companies can creates a unique selling points in an addressed market niche [8,9]. The customer receives a solution instead of products. It reduce complexity on the customer side and it guaranties a defined service level.

\section{Product and Service Lifecycle Management}

The main objective of a Product Lifecycle Management (PLM) and Service Lifecycle Management (SLM) is to provide a sound information basis to plan, control and coordinate processes and take decisions along the lifecycles of products and services. A holistic view of both PLM and SLM is necessary to involve all relevant aspects of the enterprise for an integrated development and management of PSS [3,4].There are different concepts for Product Lifecycles and Product Lifecycle Management, for example concepts that are marketing driven and consider phases like development/introduction, growth, maturity and decline [10,11]. Many of those approaches structure the lifecycles in the following main phases:

- Beginning of Life: Product Ideation, Design/Engineering, Realization/Production/ Manufacturing and Logistics/Distribution.

- Middle of Life: Use and Maintenance/Service/Support.

- End of Life: Re-use, Recycling, Remanufacturing, and Disposal.

Most traditional approaches assume that phases and steps in the lifecycle are connected in a sequential mono-directional manner, a waterfall cascading model. However, in dynamic environments there could be loops, parallels and multi-directional processes, e.g. closed loop PLM [11]. On the one hand this provides flexibility for the interactions with SLM on the other hand it increases complexity.

Service Lifecycle Management is a part of Service Science, Management and Engineering (SSME), which address the challenges coming from the servitization process $[1,2]$. A Service Lifecycle Management creates a connection between Management and Engineering and is an important discipline for providing and contributing specific knowledge about service. The three main phases are shown in the following $[17,18,19]$ :

- Service creation: Service Ideation.

- Service Engineering: Service Requirement Analysis, Design, Implementation, and Testing.

- Service Operation: Service Delivery and Evolution.

For a PSS lifecycles of products and services are linked and, as a consequence, the lifecycle managements have to be aligned to those links or even integrated. Freitag et al. (2017) provide more detailed information [19]. 


\section{$3 \quad$ Industry 4.0 and Smart Service}

This chapter focuses on the relationship between Product Lifecycle Management, e.g. in a factory based on Industry 4.0, and the Service Lifecycle Management, e.g based on a Smart Service. Here in this paper the Product-Service System (PSS) consists of a combination of Industry 4.0 and Smart Service. Fig. 1 illustrates the relationship along a Smart Service Lifecycle.

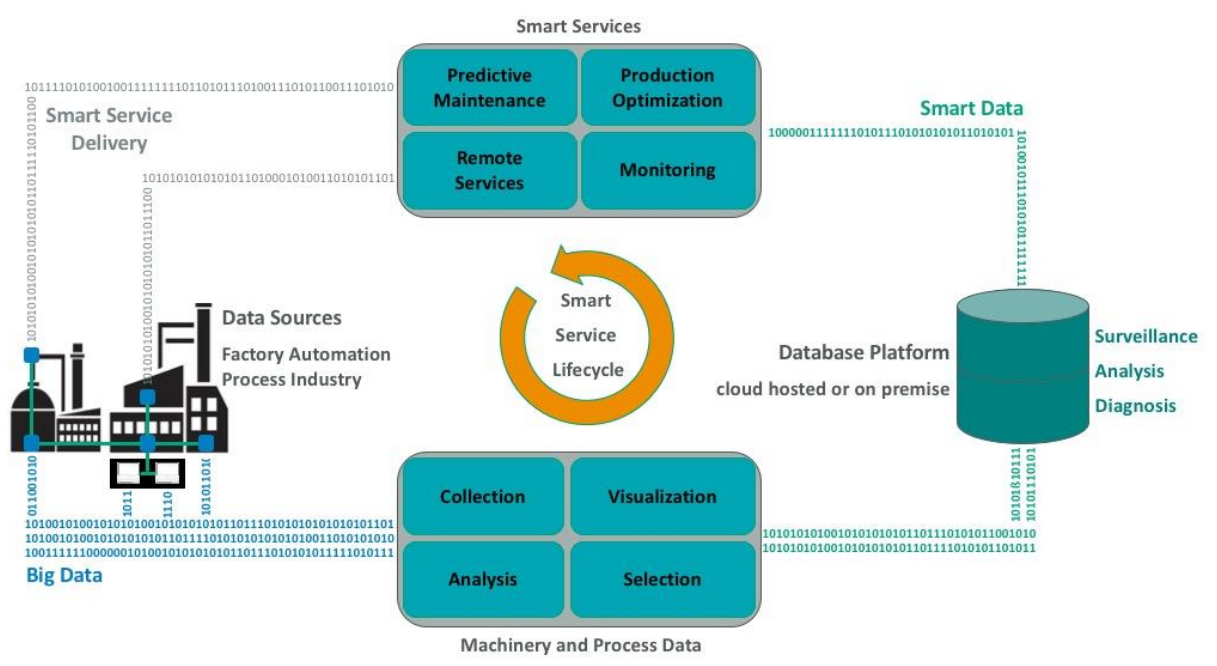

Fig. 1. Smart Service Lifecycle, adopted from [12]

In a networked factory, sensors from machines continuously send data to a database platform. Depending on the type of sensor, for example temperature, humidity or energy consumption can be measured. Depending on the configuration, the data transmission of the numerous measurement results (Big Data) can be done in real time or at fixed intervals, e.g. once a day. All transmitted data are stored on the selected platform. Not only the measured values are recorded, but also the associated metadata such as the date of the measured value and the serial number of the machine. This entire data pool is analyzed and structured at fixed intervals by using software. Only on the basis of this structured data (Smart Data) Smart Services - such as process optimizations or predictive maintenance plans - can be proposed [13]. This creates added value for the customer, even in monetary terms. The customer thus receives an individually configured service based on the collected and structured data of his machines. Based on acatech (2018) Smart Services can be defined as follows "Smart Services are connected physical or data-driven services that allow individual offerings to the customer." [14] 


\section{Empirical Evidence about Smart Service Expectations in manufacturing Industries}

In 16 expert interviews [15] conducted - mostly with representatives from small and medium-sized German enterprises - there were hardly any mentions of previously used Smart Services. However, the interviewed experts provided a first insight into the future expectations in the field of Smart Services in manufacturing industries. The following types of Smart Services have been mentioned several times:

- Remote Services,

- Production Optimization Services,

- Predictive Maintenance Services and

- Monitoring Services.

The vast majority of companies would like to offer Smart Services via service platforms in the future. On a European level, the PSYMBIOSYS research project has been working with four industrial use cases to support their transformation from product manufacturers to Product-Service System (PSS) providers [16]. An example of a Monitoring Service is given in chapter 6 , which aims at the development of video analysis and archiving Smart Services. Intended Smart Services for the other three use cases include: Production Optimization in the machine tool industry, Monitoring Services for office furniture to offer user-centric renovation projects and Production Optimization Services for the fashion industry. The support needs of the industrial partners have been analyzed to identify general requirements for the realization of these Smart Services [16], e.g.:

- Formalized PSS ideation platform

- Mechanisms to test and monitor tools and services

- Advanced PSS modelling

- New Business Models based on product servitization

A Smart Service Lifecycle Management framework, which structures the above elements among others from the idea to the replacement of a Smart Service is described in the next chapter.

\section{Development and Management of Smart Service}

One approach to develop and manage such a Smart Service Lifecycle as shown in Fig. 1 is the introduction of a Smart Service Lifecycle Management [17,18]. This Lifecycle Management does not only depict the development perspective of a Smart Service, but also the Management of the Business Model and the Network. Fig. 2 illustrates this. 


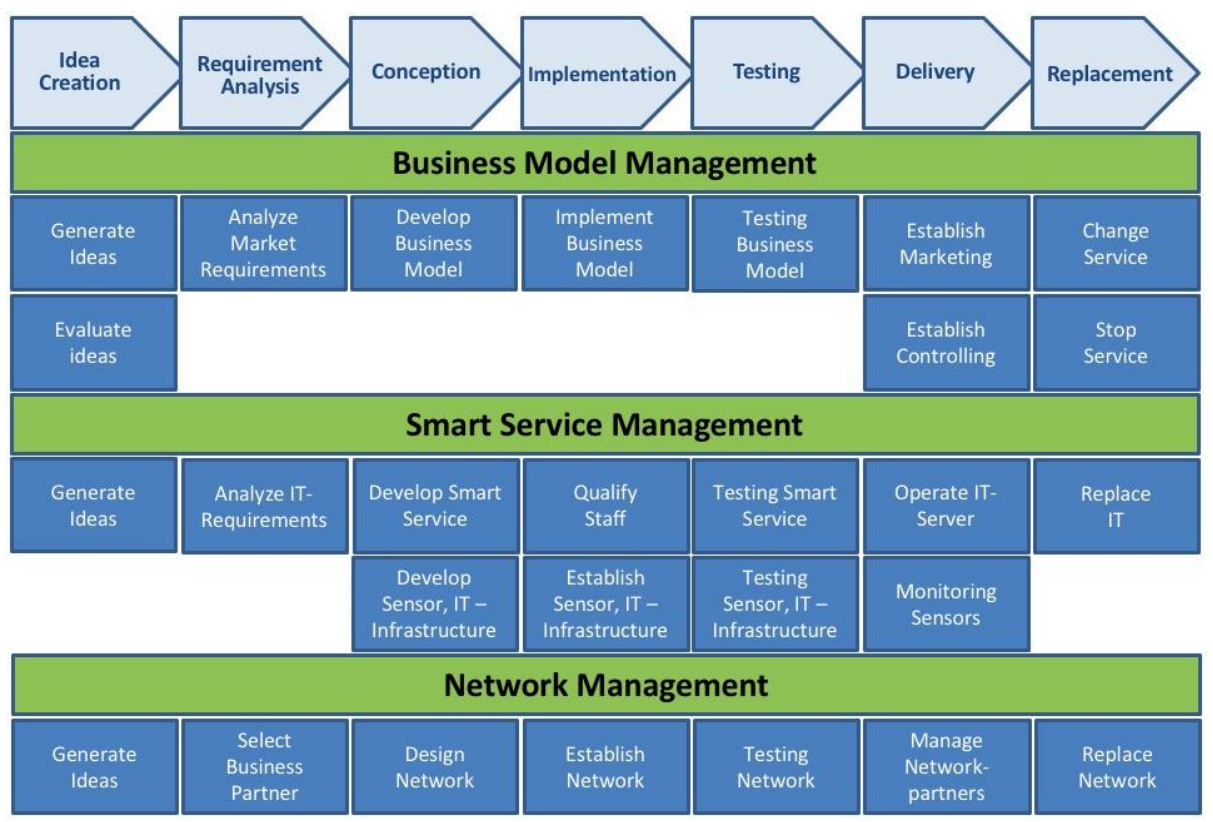

Fig. 2. Modular Process Model of a Smart Service Lifecycle Management [14]

There are three levels of Smart Service Lifecycle Management: Business Model Management, Smart Service Management and Network Management. These three levels contain a total of 28 development modules [18], which help to manage the Lifecycle of a Smart Service from Idea Creation to Delivery and Replacement.

The Smart Service lifecycle begins with an ideation stage. However, the process is not focused just on the service, but targets the Smart Service as a holistic solution. Therefore, also the Business Model and Network are considered. The same is true for the requirements stage. Starting from the market requirements, IT and partner needs for the solution will be defined. During conception, the Business Model, service and infrastructure, as well as the network are designed in parallel. Iterative feedback loops ensure design compatibility. The implementation comprises the realization of the tangible and intangible components of the Smart Service. Similar to conception, product and service realization is separated, but iterative testing of the results ensures that they can be combined. As soon as this is verified, the Smart Service can be delivered to the user. Should the Smart Service not be able to fulfil its intended function anymore, it will be replaced. Here it will be decided, if the Smart Service can be changed by replacing IT or Network, or if it has to be stopped. [19]

The above framework has been applied to configure a Smart Service Lifecycle Management by an aviation company, which is described in the following chapter 6 . 


\section{Use Case FTI}

First, the company FTI will be briefly introduced, and then it will be described how the selected Smart Service has been developed step by step [19, 20].

The FTI Engineering Network GmbH specializes in the development of camera systems for aviation. The company thus supports the safe operation of aircraft and actively contributes to the development and improvement of security and entertainment subsystems. As a certified company, the portfolio ranges from individual components to customized complete systems.

The development activities in the area of Smart Services are driven in particular by the desired video-based surveillance solutions in aircraft. In terms of easy integration into the aircraft and maximum scalability, the monitoring system is based on a modular system architecture. It is also proving beneficial for the addition of smart services to the product portfolio due to possible separation between the flying device and the infrastructure on the ground. It is therefore possible to develop a customer-specific Smart Service. Depending on the target group, these services convince through their functionalities and their innovative billing models $[19,20]$. The basic idea for the necessary infrastructure is shown in Fig. 3.

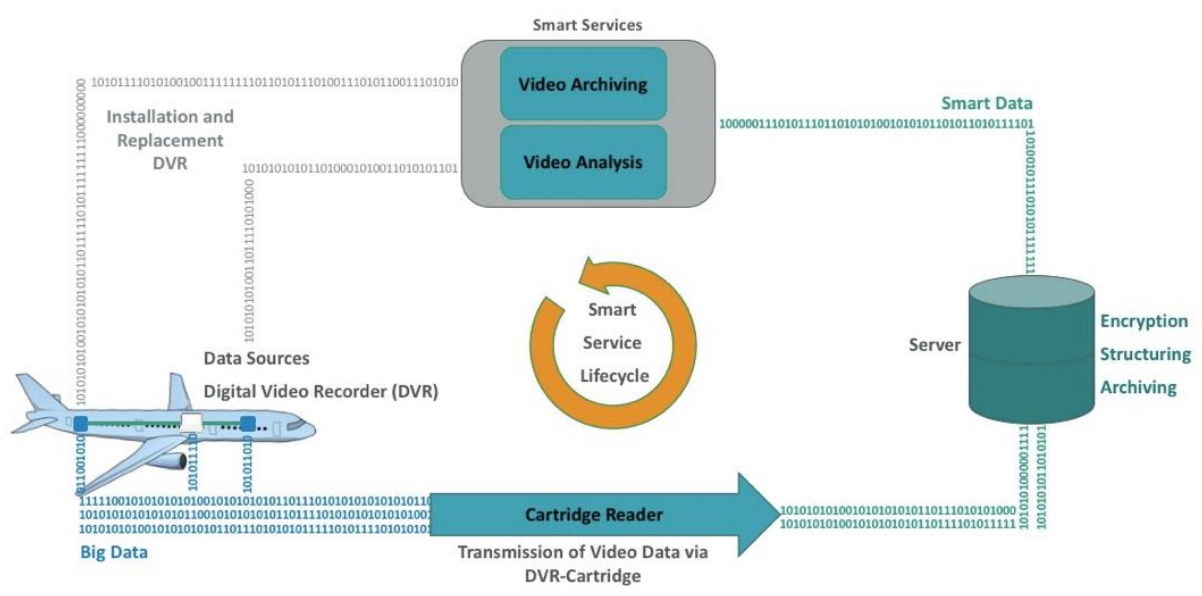

Fig. 3. Smart Service Lifecycle of FTI Engineering Network GmbH

After the aircraft landing, all data from the Digital Video Recorder (DVR) are transferred to an archiving server. For this purpose, the memory module (Memory Cartridge) must be removed from the DVR and inserted into a mobile reading device (Cartridge Reader). The Cartridge Reader can be connected via standard interfaces to standard computer platforms. A video analysis software allows access to the encrypted video data. The software will also provide access to the services that will be unlocked for each user and billed according to their usage. In this context, the server will provide the database needed to run the services. Taking into account the use by different customers, the server will ensure the strict separation of company data. The customer does not have 
to provide any specific computer technology - only an internet connection is needed. Interesting price models will keep costs down for the customer while generating new revenues for FTI [15].

To develop and manage this new Smart Service, the Smart Service Lifecycle Management - described above - was used. So far 10 of the 28 modules have been selected and adapted to FTI. First pilot customers in the aviation industry have already used both video analysis and video archiving. At the end it was validated by FTI that the Service Lifecycle Management can structure the developing process and integration of the customer in the development process, e.g. to identify the right business model and accepted Service Level Agreement.

\section{$7 \quad$ Summary}

This paper has depicted the growing importance of offering Smart Services by manufacturing companies, which are enabled through the increasing amount of data available following Industry 4.0 implementation. The ability to offer Smart Services creates a competitive advantage for a company, as it can provide individually configured valueadded services to the customer. However, expert interviews and work with industrial use cases shows that the knowledge how to realize such Smart Services is still rudimental, in spite of high expectations. Therefore, a Smart Service Lifecycle Management is introduced, formalizing the support needs of the industry and the phases of the lifecycle in a framework, covering business, service and network elements. Parts of this framework have been successfully applied to develop a Monitoring Service for an industrial use case in video surveillance.

Although the Smart Service Lifecycle Management has also been tested with good results in other use cases, it is important to mention that it only provides a conceptual framework for Smart Service realization. In future research, methods and tools have to be further developed to support every element of the lifecycle for companies aiming to offer Smart Services. Standardized interfaces are needed to provide a seamless workflow along the lifecycle and between the different systems for the product, service, business and networking aspects.

Acknowledgements. This work has been partly funded by the European Commission through the FoF-Project "PSYMBIOSYS" (No. 636804) and by the German Federal Ministry of Education and Research (BMBF) through the Project "iSrv. Intelligente Servicesysteme" (No. 169110). The authors wish to acknowledge the Commission, the Ministry and all the project partners for their contribution.

\section{References}

1. Spohrer, J.C., Maglio, P.P.: Toward a Science of Service Systems. In: Kieliszewski, C. A. et al.: Handbook of service science, pp .157-194, Springer Verlag, New York (2010).

2. Freitag M., Ganz W.: InnoScore ${ }^{\circledR}$ service. Evaluating innovation for product-related services. In: Service Research \& Innovation Institute (Eds): Annual SRII global conference 2011, proceedings IEEE, pp. 214-221, Piscataway, NJ (2011). 
3. Qu M., Yu S., Chen D., Chu J., Tian B.: State-of-the-art of design, evaluation, and operation methodologies in product service systems. Computers in Industry 77, 1-14 (2016).

4. Pezzotta G., Pirola F., Pinto R., Akasaka F., Shimomura Y.: A Service Engineering framework to design and assess an integrated product-service. Mechatronics 31, 169-179 (2015).

5. Pezzotta G., Pinto R., Pirola F., Ouertani M.Z.: Balancing product-service provider's performance and customer's value: The service engineering methodology (SEEM). Procedia CIRP 16, 50-55 (2014).

6. Wiesner, S., Freitag, M., Westphal, I., Thoben, K.-D.: Interactions between service and product lifecycle management. Procedia CIRP 30, 36-41 (2015).

7. Westphal I., Freitag M., Thoben K.-D.: Visualization of interactions between product and service lifecycle management. IFIP Advances in Information and Communication Technology 2015, 460, 575-582 (2015).

8. Goedkoop, M.J., van Halen, C.J.G., te Riele, H.R.M., Rommens, P.J.M.: Product service systems, ecological and economic basics (1999)

9. Tukker, A.: Eight types of product-service system: eight ways to sustainability? Experiences from SusProNet. Bus. Strategy Environ. 13(4), 246-260 (2004)

10. Stark, J.: Product Lifecycle Management: 21st Century Paradigm for Product Realisation. Springer, New York (2011)

11. Kiritsis, D.: Closed-loop PLM for intelligent products in the era of the internet of things. Comput. Aided Des. 43(5), 479-501 (2011)

12. ZVEI (The German Electrical and Elektronic Industry Association), https://www.zvei.org/fileadmin/user_upload/Presse_und_Medien/Publikationen/2016/Dezember/Industrie_4.0__Smart_Services/Industrie-40-Smart-Services.pdf, last accessed 2018/04/02.

13. Wiesner, S., Thoben, K.-D.: Cyber-Physical Product-Service Systems. In: Biffl, S., Lüder, A., Gerhard, D. (eds.) Multi-Disciplinary Engineering for Cyber-Physical Production Systems, pp. 63-88. Springer International Publishing, Cham (2017)

14. acatech Homepage, http://www.acatech.de/fileadmin/user_upload/Baumstruktur_nach_Website/Acatech/root/de/Projekte/Laufende_Projekte/Smart_Service_Welt/BerichtSmartService_mitUmschlag_barrierefrei_HW76_DNK2.pdf, last accessed 2018/04/09.

15. iSrv. Intelligente Servicesysteme, https://www.isrv.info/, last accessed 2018/04/09.

16. Wiesner S., Nilsson S., Thoben K.-D.: Integrating Requirements Engineering for Different Domains in System Development - Lessons Learnt from Industrial SME Cases. Procedia CIRP 64, 351-356 (2017).

17. Freitag M., Kremer D., Hirsch M., Zelm M.: An Approach to Standardise a Service Life Cycle Management. In: Martin Zelm, Marten van Sinderen, Luis Ferraira Pires, Guy Doumeingts (Eds.). Enterprise Interoperability, pp. 115-126, John Wiley \& Sons, Chichester (2013).

18. Freitag, M., Hämmerle, O.: Smart Service Lifecycle Management. Ein Vorgehensmodell für produzierende Unternehmen, wt Werkstattstechnik online 106(7/8), 477-482 (2016).

19. Freitag, M., Hämmerle, O., Hans, Carl: Smart Service Lifecycle Management in der Luftfahrtindustrie. In: Smart Services und Internet der Dinge: Geschäftsmodelle, Umsetzung und Best Practices, pp. 73-89, Carl Hanser Verlag, München (2017).

20. Hans C., Kirste, S., Westphal, I., Wiesner, S.: Product-Service Systems - neue Marktpotenziale für den Mittelstand. In: Jahresbericht der Gemeinnützigen Gesellschaft zur Förderung des Forschungstransfers e.V., pp. 22-27, online https://www.gfft-portal.de/wp-content/uploads/2017/11/2015_2016-Jahresbericht_0.pdf, last accessed 2018/06/08 